\title{
ELK3 promotes the migration and invasion of liver cancer stem cells by targeting HIF-1 $\alpha$
}

\author{
JOON HO LEE, WONHEE HUR, SUNG WOO HONG, JUNG-HEE KIM, SUNG MIN KIM, \\ EUN BYUL LEE and SEUNG KEW YOON
}

\begin{abstract}
The Catholic University Liver Research Center and WHO Collaborating Center of Viral Hepatitis, College of Medicine, The Catholic University of Korea, Seoul 06591, Republic of Korea
\end{abstract}

Received May 18, 2016; Accepted June 25, 2016

DOI: $10.3892 /$ or.2016.5293

\begin{abstract}
Hepatocellular carcinoma (HCC) is the fifth most common solid cancer and the third most common cause of cancer-related mortality. HCC develops via a multistep process associated with genetic aberrations that facilitate HCC invasion and migration and promote metastasis. A growing body of evidence indicates that cancer stem cells (CSCs) are responsible for tumorigenesis, cancer cell invasion and metastasis. Despite the extremely small proportion of cancer cells represented by this subpopulation of HCC cells, CSCs play a key role in cancer metastasis and poor prognosis. ELK3 (Net/SAP-2/Erp) is a transcription factor that is activated by the Ras/extracellular signal-regulated kinase (ERK) signaling pathway. It plays several important roles in various physiological processes, including cell migration, invasion, wound healing, angiogenesis and tumorigenesis. In the present study, we investigated the role of ELK3 in cancer cell invasion and metastasis in $\mathrm{CD}_{133}{ }^{+} / \mathrm{CD}_{4} 4^{+}$liver cancer stem cells (LCSCs). We isolated LCSCs expressing CD133 and CD44 from Huh7 HCC cells and evaluated their metastatic potential using invasion and migration assays. We found that $\mathrm{CD} 133^{+} / \mathrm{CD} 44^{+}$cells had increased
\end{abstract}

Correspondence to: Professor Seung Kew Yoon, The Catholic University Liver Research Center and WHO Collaborating Center of Viral Hepatitis, College of Medicine, The Catholic University of Korea, Seoul 06591, Republic of Korea

E-mail:yoonsk@catholic.ac.kr

Abbreviations: HCC, hepatocellular carcinoma; CSCs, cancer stem cells; HIF-1 $\alpha$, heat shock induced factor-1 $\alpha$; TCF, ternary complex factor; MAPK, mitogen-activated protein kinase; ERK, extracellular signal-regulated kinase; LCSCs, liver cancer stem cells; egr-1, early growth response protein-1; PAI-1, plasminogen activator inhibitor-1; EMT, epithelial-mesenchymal transition; ECM, extracellular matrix; VEGF, vascular endothelial growth factor; MMP-2, metalloproteinase-2; siRNA, small interfering RNA; bFGF, basis fibroblast growth factor; EGF, epidermal growth factor; RT-PCR, reverse transcription-polymerase chain reaction; ELISA, enzyme-linked immunosorbent assay

Key words: cancer stem cell, ELK3, metastasis, invasion, hepatocellular carcinoma, HIF- $1 \alpha$ metastatic potential compared with non-CD133 $/ \mathrm{CD} 44^{+}$cells. We also demonstrated that ELK3 expression was upregulated in $\mathrm{CD} 33^{+} / \mathrm{CD} 44^{+}$cells and that this aberration enhanced cell migration and invasion. In addition, we identified the molecular mechanism by which ELK3 promotes cancer cell migration and invasion. We found that silencing of ELK3 expression in $\mathrm{CD} 133^{+} / \mathrm{CD}_{4} 4^{+} \mathrm{LCSC}$ attenuated their metastatic potential by modulating the expression of heat shock-induced factor-1 $\alpha$ (HIF-1 $\alpha$ ). Collectively, the results of the present study demonstrated that ELK3 overexpression promoted metastasis in $\mathrm{CD} 133^{+} / \mathrm{CD} 44^{+}$cells by regulating $\mathrm{HIF}-1 \alpha$ expression and that silencing of ELK3 expression attenuated the metastatic potential of $\mathrm{CD} 33^{+} / \mathrm{CD} 44^{+} \mathrm{LCSC}$. In conclusion, modulation of ELK3 expression may represent a novel therapeutic strategy for preventing HCC metastasis and invasion.

\section{Introduction}

Hepatocellular carcinoma (HCC) is the fifth most common solid cancer and the third most common cause of cancerrelated mortality (1). The current treatment modalities for HCC, including liver transplantation, surgical resection and local ablation therapy, have significantly prolonged patient survival $(2,3)$. However, when liver cancer spreads within the liver or to other organs, effective therapeutic options are extremely limited, and the mortality rate is high (4). Although the risk factors predisposing patients to HCC have been well established, the precise molecular mechanisms underlying HCC metastasis are not fully understood. Therefore, a better understanding of the molecular processes associated with $\mathrm{HCC}$ invasion and metastasis is required for the development of effective therapeutic strategies to treat metastatic $\mathrm{HCC}$ and prolong patient survival.

Cancer stem cells (CSCs) represent a small subpopulation of cancer cells in various types of cancer. CSCs are distinguished by their capacity to self-renew and differentiate into malignant cells. Despite composing only a small proportion of the general population of cancer cells, CSCs make a significant contribution to cancer metastasis and invasion due to their high metastatic potential (5-7). To date, various cell surface markers specifically expressed on CSCs, including CD133, CD44, EpCAM and CD90, have been identified, and each of these markers has been biologically and clinically characterized (8). 
The 5-transmembrane protein CD133, also referred to as human prominin-1, is a well-established protein marker of multiple types of solid tumors (9). In addition, CD133 has been shown to mediate $\mathrm{HCC}$ metastasis by regulating the expression of metastasis-associated genes, and CD133 expression in HCC is associated with a poor prognosis (10-12). In our previous study, we demonstrated that Huh $7^{\mathrm{CD} 133^{+}}$liver cancer stem cells (LCSCs) exhibit greater metastatic potential compared with Huh7 ${ }^{\mathrm{CD} 133^{-}}$cells after undergoing radiation treatment in vitro and in vivo (13). The transmembrane glycoprotein CD44 localizes to the cell surface and plays a key role in various intracellular interactions, including cell adhesion and migration $(14,15)$. CD44 is expressed not only in HCC cells but in other types of cancers as well, such as colorectal and breast cancer $(14,16,17)$. Therefore, we focused the present study on the role of the cell surface markers CD133 and CD44 in HCC metastasis.

ELK3, also referred to as SAP-2, Net or Erp, forms a ternary complex factor (TCF) along with ELK1 and ELK4 (18). ELK3 is activated by mitogen-activated protein kinase (MAPK)-associated pathways, such as the Ras/extracellular signal-regulated kinase (ERK) and p38 pathways, and it plays an important role in various physiological processes, including cell migration, invasion, wound healing, angiogenesis and tumorigenesis, via the regulation of c-fos, early growth response protein 1 (egr-1), and plasminogen activator inhibitor-1 (PAI-1) (19-23). Mutations in ELK3 disrupt vasculogenesis, angiogenesis and wound healing in mice during development and in adulthood (24,25). In addition, our previous study demonstrated that ELK3 contributes to epithelial-mesenchymal transition (EMT) of mouse hepatocytes by regulating egr-1 (26). EMT, a process whereby epithelial cells reduce their intercellular adhesions and gain mesenchymal properties, is a critical event in the process of cancer invasion and metastasis $(27,28)$. During liver cancer metastasis, epithelial cell-like HCC cells gain a mesenchymal phenotype characterized by an increase in cell migration and the ability to degrade the extracellular matrix (ECM) $(27,29)$. These observations suggest that EMT may play an important role in $\mathrm{HCC}$ metastasis. Moreover, recent studies revealed that ELK3 is associated with the regulation of hypoxia-induced factor $1 \alpha(\mathrm{HIF}-1 \alpha)(30,31)$. HIF-1 $\alpha$ is a transcription factor that plays a well-established role in cancer development, progression and metastasis. HIF- $1 \alpha$ is associated with the regulation of genes associated with cancer metastasis, invasion, angiogenesis, cellular proliferation, apoptosis and glucose metabolism (32-36). Vascular endothelial growth factor (VEGF) and metalloproteinase-2 (MMP-2), which are target molecules of HIF-1 $\alpha$, are also linked to the development, invasion and metastasis of HCC (35-38). Although ELK3 is known to be involved in cell migration and invasion, the influence of ELK3 on the metastatic potential of LCSCs remains unclear. Therefore, we investigated the role of ELK3 in LCSC metastasis and found that ELK3 can attenuate the metastatic potential of LCSCs.

\section{Materials and methods}

Cell culture. Huh7 and Hep3B HCC cells were grown in Dulbecco's modified Eagle's medium (DMEM) supplemented with $10 \%$ fetal bovine serum (FBS), $100 \mu \mathrm{g} / \mathrm{ml}$ penicillin and $0.25 \mu \mathrm{g} / \mathrm{ml}$ streptomycin (all from Invitrogen, Carlsbad, CA, USA). SKHep1, HepG2 and PLC/PRF/5 cells were grown in minimum essential medium (MEM) supplemented with $10 \%$ FBS, $100 \mu \mathrm{g} / \mathrm{ml}$ penicillin and $0.25 \mu \mathrm{g} / \mathrm{ml}$ streptomycin (all from Invitrogen). All of the cell lines were maintained at $37^{\circ} \mathrm{C}$ in an atmosphere of $5 \% \mathrm{CO}_{2}$.

RNA interference. The small interfering RNA (siRNA) method was used to knock down the expression of ELK3. Three different siRNAs targeting ELK3 (5'-CCAAGAUCUCCU CUUUAAUtt-3'; 5'-GGACUCAUUAACUGAUGAAtt-3'; and 5'-GGUCUCUAGUAGAAUUUCAtt-3') (Santa Cruz Biotechnology, Santa Cruz, CA, USA) were pooled together and used at a final concentration of $30 \mathrm{nM}$. Control cells were subjected to mock transfection with scrambled siRNA. The cells were transfected using G-fectin (Genolution Pharmaceuticals, Seoul, Korea) according to the manufacturer's protocol.

Cell isolation using fluorescence-activated cell sorting (FACS) analysis. The cells were harvested using $0.5 \mathrm{mM}$ trypsin/EDTA (Invitrogen) and subsequently incubated with phycoerythrin (PE)-conjugated anti-CD133/1 and allophycocyanin (APC)-conjugated anti-CD44 (Miltenyi Biotec, Auburn, CA, USA) at $4^{\circ} \mathrm{C}$ for $10 \mathrm{~min}$. The LCSCs were sorted from the Huh7 cells using flow cytometry (MoFlo XDP; Beckman Coulter, Miami, FL, USA) with antibodies against CD133/1 and CD44. An isotype-matched mouse IgG was used as the negative control.

Sphere formation assay. The cells were seeded in multiple ultra-low attachment 24-well plates (Corning Costar Corp., Cambridge, MA, USA) at a density of $2 \times 10^{2}$ cells/well in serum-free DMEM/F12K with B27 supplement (both from Invitrogen), basis fibroblast growth factor (bFGF) $(20 \mathrm{ng} / \mathrm{ml})$ and epidermal growth factor (EGF) $(20 \mathrm{ng} / \mathrm{ml})$ (both from PeproTech, Rocky Hill, NJ, USA). The cells were incubated at $37^{\circ} \mathrm{C}$ in an atmosphere of $5 \% \mathrm{CO}_{2}$ for 5 days. Then, the spheres (diameter $>50 \mu \mathrm{m}$ ) in each well were counted using an inverted microscope (Olympus, Tokyo, Japan). The average number of spheres was calculated from three independent experiments.

Migration assays. Isolated Huh7 cells were grown for 3 days in $10 \%$ FBS complete medium. Then, the cells were harvested using $0.5 \mathrm{mM}$ trypsin/EDTA (Invitrogen) and resuspended in serum-free medium. Cell migration was evaluated using 6.5-mm Transwell plates with $8-\mu \mathrm{m}$ pore size filters (Corning Costar Corp.). The resuspended cells were seeded into the upper chamber $\left(3 \times 10^{4}\right.$ cells) of the Transwell, and $600 \mu \mathrm{l}$ of $10 \%$ FBS complete medium was added to the bottom chamber and used as a chemoattractant. The cells were incubated for $48 \mathrm{~h}$ at $37^{\circ} \mathrm{C}$ in an atmosphere of $5 \% \mathrm{CO}_{2}$. The cells that had not migrated were removed using a cotton swab. The cells that had migrated were stained using a Diff-Quick ${ }^{\mathrm{TM}}$ ThreeStep Stain kit (Sysmex, Kobe, Japan) and mounted on glass slides. The cells in 4 randomly selected fields (magnification, $\mathrm{x} 200$ ) from each slide were quantified using a slide scanner (Pannoramic MIDI; 3DHISTECH Ltd., Budapest, Hungary). 
Table I. Proportion of $\mathrm{CD} 133^{+}, \mathrm{CD}_{4} 4^{+}$and $\mathrm{CD} 133^{+} / \mathrm{CD} 44^{+}$cells in the $\mathrm{HCC}$ cell lines.

\begin{tabular}{lccrrr}
\hline & \multicolumn{5}{c}{ Cell lines (\%) } \\
\cline { 2 - 6 } Markers & Huh7 & PLC/PRF/5 & HepG2 & SKHep1 & Hep3B \\
\hline CD133 $^{+}$ & $42.3 \pm 3.9$ & $74.6 \pm 15.3$ & $15.1 \pm 4.7$ & $3.0 \pm 0.6$ & $0.6 \pm 0.4$ \\
$\mathrm{CD}^{+}$ & $21.3 \pm 2.9$ & $2.1 \pm 0.7$ & $7.1 \pm 2.5$ & $99.1 \pm 0.6$ & $99.6 \pm 0.3$ \\
$\mathrm{CD}^{+} 33^{+} / \mathrm{CD} 44^{+}$ & $11.1 \pm 1.3$ & $1.8 \pm 0.5$ & $1.6 \pm 0.9$ & $2.8 \pm 0.6$ & $0.6 \pm 0.2$ \\
\hline
\end{tabular}

HCC, hepatocellular carcinoma.

Invasion assays. The Transwell invasion assays were conducted using a Transwell plate (Corning Costar Corp.) coated with Matrigel (BD Biosciences, San Jose, CA, USA) according to the manufacturer's instructions. Briefly, the Matrigel (BD Biosciences) was diluted with serum-free medium at a dilution of 1:5, added to the upper chamber, and incubated at $37^{\circ} \mathrm{C}$ until it had completely solidified. The unbound Matrigel was removed by washing. Cells in serum-free medium were seeded into the upper chamber $\left(5 \times 10^{4}\right.$ cells $)$, and $600 \mu \mathrm{l}$ of complete medium was added to the bottom chamber and used as a chemoattractant. The cells were incubated for $48 \mathrm{~h}$ at $37^{\circ} \mathrm{C}$ in an atmosphere of $5 \% \mathrm{CO}_{2}$, and the non-invasive cells were removed using a cotton swab. The cells that had invaded the membrane were stained using a Diff-Quick ${ }^{\mathrm{TM}}$ Three-Step Stain kit and mounted on glass slides. The stained cells were counted using a slide scanner (Pannoramic MIDI) (magnification, $\mathrm{x} 200)$.

Western blotting. The protein extracts were separated using 8\% SDS-PAGE and transferred to nitrocellulose membranes (Schleicher \& Schuell, Dassel, Germany). The membranes were blocked in 5\% skim milk and incubated with the indicated primary antibodies according to the manufacturer's protocol. The following primary antibodies were used in the western blot assays: anti-ELK3, anti-VEGF (both from Abcam, Cambridge, MA, USA), anti-HIF-1 $\alpha$ (Santa Cruz Biotechnology) and anti- $\beta$-actin (Sigma, St. Louis, MO, USA). The membranes were subsequently incubated with horseradish peroxidase (HRP)-conjugated anti-mouse or antirabbit secondary antibodies (Santa Cruz Biotechnology). The target proteins were visualized using an enhanced chemiluminescence reagent (Amersham Biosciences, Cardiff, UK). The density of each band was measured using Multi Gauge imaging software (Raytest, Straubenhardt, Germany).

Reverse transcription polymerase chain reaction (RT-PCR). Total RNA was purified from $\mathrm{CD} 133^{+} / \mathrm{CD}_{4} 4^{+}$and CD133\%CD44- cells using TRIzol reagent (Invitrogen). The cDNA was synthesized from $2 \mu \mathrm{g}$ of total RNA, and ELK3 was amplified using PCR with ELK3-specific primers (forward, 5-ACCCAAAGGCTTGGAAATCT-3 and reverse, 5-TGTATGCTGGAGAGCAGTGG-3'). The expression level of the target gene was normalized to the expression of the $\beta$-actin internal control. $\beta$-actin was amplified using PCR with $\beta$-actin-specific primers (forward, 5'-GGCACCCACCCTTC TACATAGA-3' and reverse, 5'-CCCTCGTAGATGGGCAC
ACT-3'). The PCR products were separated using electrophoresis on a $1 \%$ agarose gel with $0.5 \mu \mathrm{g} / \mathrm{ml}$ ethidium bromide (Research Genetics, Huntington, AL, USA) and visualized using a Gel-Doc system (Bio-Rad, Vienna, Austria).

VEGF enzyme-linked immunosorbent assay (ELISA). Human VEGF Quantikine ELISA kits (R\&D Systems, Minneapolis, MN, USA) were used to measure VEGF levels in cell supernatants according to the manufacturer's instructions. Briefly, $200 \mu 1$ of the harvested cell supernatants was dispensed into wells coated with coating buffer and incubated for $2 \mathrm{~h}$ at room temperature (RT). After the wells were completely washed, the VEGF conjugate was dispensed into each well, and the wells were incubated at RT. Then, the plates were developed using substrate solution for $20 \mathrm{~min}$. The absorbance at $450 \mathrm{~nm}$ was measured using a microplate reader.

Gelatin zymography. The cell supernatants were collected and mixed with non-denatured sample buffer $[1 \mathrm{M}$ Tris- $\mathrm{Cl}$ (pH 6.8), 1\% bromophenol blue and 20\% SDS]. The resulting cell supernatant solution was separated on a polyacrylamide gel containing $1 \mathrm{mg} / \mathrm{ml}$ gelatin (Sigma). The gels were renatured with $2.5 \%$ Triton $\mathrm{X}-100$ and incubated in activation buffer [50 mM Tris buffer (pH 7.4), $5 \mathrm{mM} \mathrm{CaCl}_{2}$ and $1 \mu \mathrm{M} \mathrm{ZnCl}_{2}$ ) at $37^{\circ} \mathrm{C}$ for $12 \mathrm{~h}$. Then, the gels were stained with Coomassie Brilliant Blue R-250 for 20 min and destained with destaining buffer (45\% methanol and 10\% acetic acid). MMP-2 appeared as a clear area and the band density was measured using Multi Gauge imaging software.

Statistical analysis. The data are presented as the mean \pm SD. of at least 3 separate experiments. The statistical analyses were conducted using a two-tailed Student t-test. $\mathrm{p}<0.05$ and $\mathrm{p}<0.01$ indicate statistical significance.

\section{Results}

CD133+ ${ }^{+}$CD $44^{+}$LCSCs are more clonogenic compared with non- $C D 133^{+} / C D 44^{+}$cells. To identify a putative marker of LCSCs, we evaluated the expression of the cell surface markers CD133 and CD44 in 5 HCC cell lines using flow cytometry. The expression of CD133 and CD44 was significantly different in each cell line. As shown in Table I, the proportion of $\mathrm{CD}_{133^{+}}$cells was highest in the PLC/PRF/5 cells $(74.6 \%)$ and lowest in the Hep3B cells $(0.6 \%)$, whereas the proportion of $\mathrm{CD} 44^{+}$cells was highest in the Hep3B 


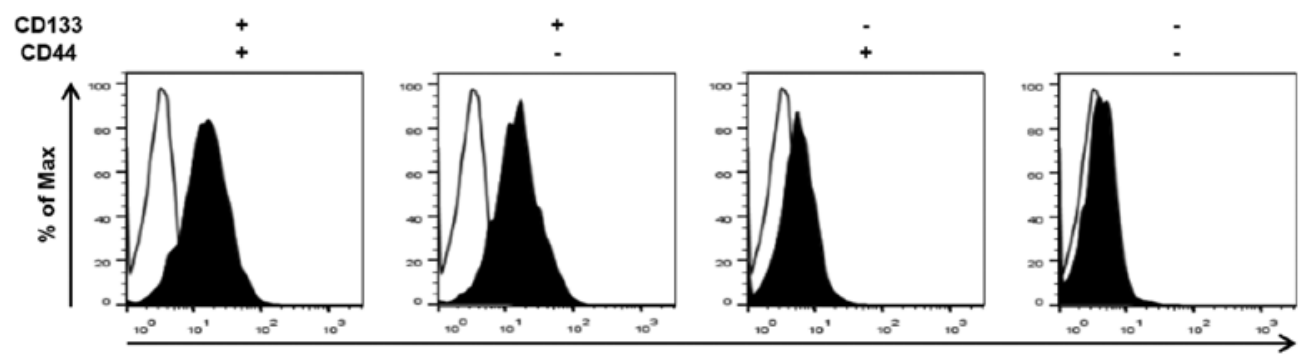

CD133-PE
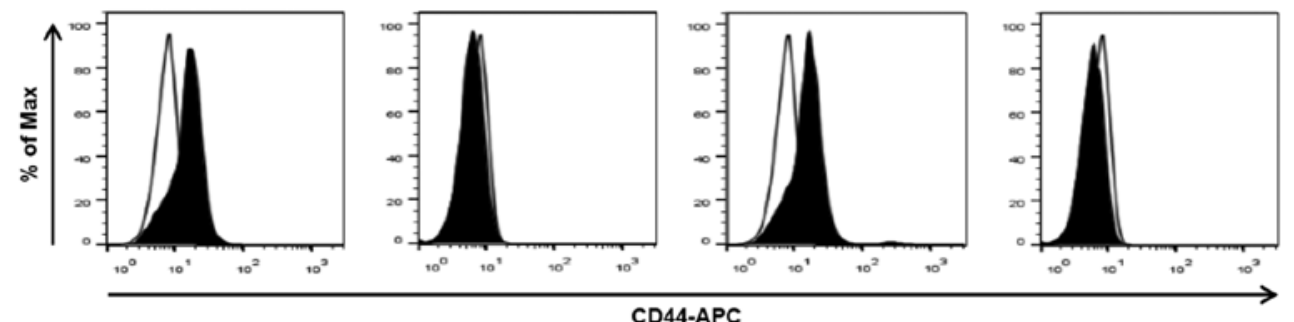

B

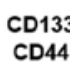

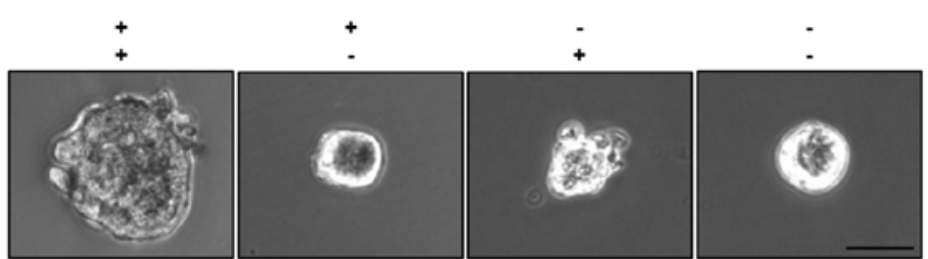

C

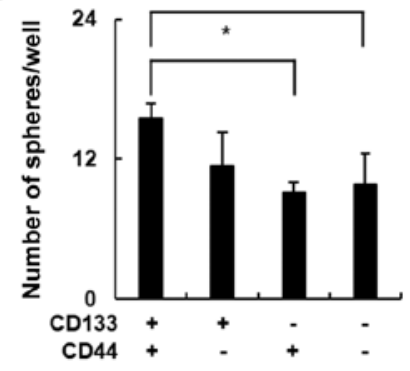

Figure 1. Correlation of clonogenic potential and CD133 and CD44 cell surface marker expression in Huh7 HCC cells. (A) The percentages of CD133 ${ }^{+} / \mathrm{CD} 44^{+}$,

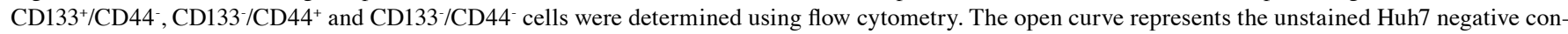
trol cells. The solid curve represents the indicated subpopulation. (B) The clonogenic potential of the 4 subpopulations was determined using sphere formation assays. Representative images of the spheres that were obtained using an inverted microscope (Olympus). Scale bar, $50 \mu \mathrm{m}$. (C) Sphere formation efficiency was quantitatively analyzed. The number of spheres (diameter $>50 \mu \mathrm{m})$ per well $\left(2 \times 10^{2}\right.$ cells/well) was determined using an inverted microscope (Olympus). The results are expressed as the means $\pm \mathrm{SD}$ of three independent experiments; " $\mathrm{p}<0.05$, CD133 ${ }^{+} / \mathrm{CD} 44^{+}$vs. $\mathrm{CD} 133^{-} / \mathrm{CD} 44^{-}$cells and $\mathrm{CD} 133^{+} / \mathrm{CD} 44^{+}$vs $\mathrm{CD} 1333^{-/ \mathrm{CD}} 44^{+}$.

cells (99.6\%) and lowest in the PLC/PRF/5 cells (2.1\%). The proportion of $\mathrm{CD}_{133^{+}} / \mathrm{CD} 44^{+}$cells was highest in the Huh7 cells (11.1\%) and lowest in the Hep3B cells $(0.6 \%)$. As the co-expression of 2 or more CSCs markers is more specific compared with the presence of a single LCSCs marker, we selected the Huh7 cell line for further experiments. To explore the biological properties of the $\mathrm{CD} 133^{+} / \mathrm{CD} 44^{+}$LCSC subpopulation of Huh7 cells, we compared the clonogenic potential of $\mathrm{CD} 133^{+} / \mathrm{CD} 44^{+}$Huh7 cells and non-CD133 ${ }^{+} / \mathrm{CD} 44^{+}$Huh7 cells. Huh7 cells were sorted into 4 subgroups according to the expression of the CD133 and CD44 surface markers using flow cytometry (Fig. 1A), and the clonogenic potential of the subgroups was examined using the sphere formation assay. The $\mathrm{CD}^{3} 3^{+} / \mathrm{CD} 44^{+}$subgroup formed the largest spheres (Fig. 1B). In addition, the number of spheres was significantly higher in the $\mathrm{CD} 133^{+} / \mathrm{CD} 44^{+}$subgroup (15 spheres/well) compared with the CD133/CD44 subgroup (9 spheres/well) (Fig. 1C). These results demonstrated that $\mathrm{CD} 133^{+} / \mathrm{CD} 44^{+} \mathrm{LCSC}$ s have greater clonogenic potential compared with non-CD133 ${ }^{+} / \mathrm{CD} 44^{+}$cells.

CD133+ ${ }^{+} \mathrm{CD} 44^{+}$LCSCs exhibit greater metastatic potential compared with non-CD133+/CD44+ cells. Recent studies have revealed that high expression levels of CD133 or CD44 contribute to CSC-associated cancer metastasis and invasion $(10,14,39)$. Therefore, we performed in vitro Transwell migration and invasion assays to evaluate the metastatic potential of the Huh7 cell subpopulations. The migratory cells in each well were stained using a Diff-Quick Three-Step stain (Fig. 2A, upper panel), and the number of migratory cells in each group were compared. The number of migratory cells in the $\mathrm{CD} 33^{+} / \mathrm{CD} 44^{+}$subgroup increased $\sim 4$-fold compared with the number in the CD133/CD44 subgroup (Fig. 2B; p<0.01). The results obtained from the Matrigel-coated Transwell invasion assay were consistent with these findings. The number of $\mathrm{CD} 133^{+} / \mathrm{CD} 44^{+}$cells that invaded the Matrigel was significantly greater compared with this number in the non-CD133 $/$ $\mathrm{CD}_{4} 4^{+}$subgroups (Fig. 2A, lower panel). The number of invasive cells in the $\mathrm{CD} 133^{+} / \mathrm{CD} 44^{+}$subgroup was $\sim 4$-fold greater when compared with the CD133/CD44- subgroup (Fig. 2B; $\mathrm{p}<0.05)$. Together, these results indicated that the cell migration and invasion activities were significantly elevated in the CD $133^{+} / \mathrm{CD} 44^{+}$LCSCs.

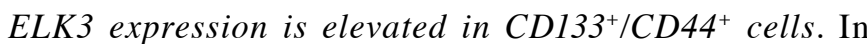
a previous study, we demonstrated that ELK3 expression plays an important role in the process of EMT during liver 


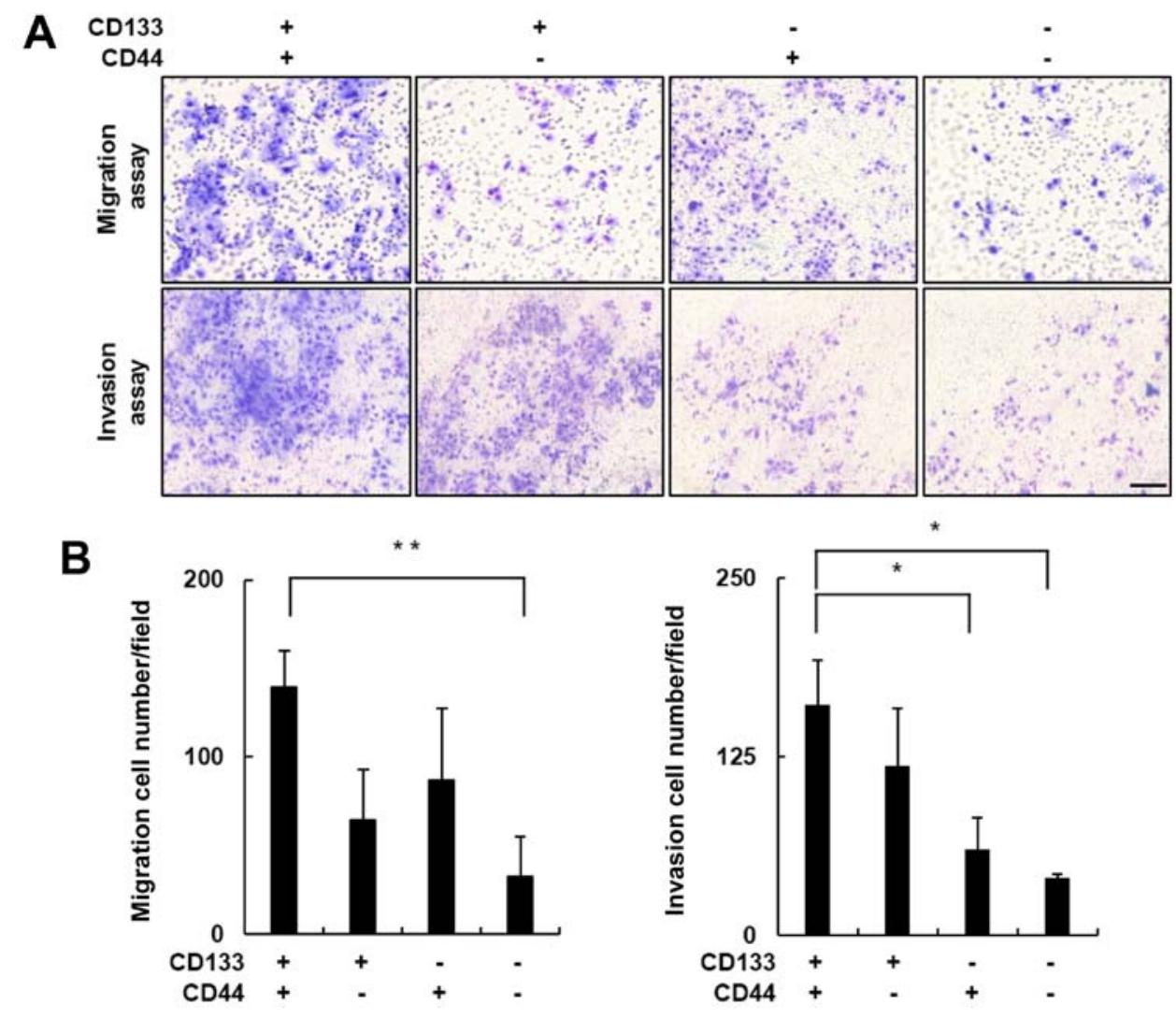

Figure 2. $\mathrm{CD} 133^{+} / \mathrm{CD} 44^{+} \mathrm{CSC}$ exhibit the highest metastatic potential. The migration and invasion activities in the $\mathrm{CD} 133^{+} / \mathrm{CD}_{4} 4^{+}, \mathrm{CD} 133^{+} / \mathrm{CD} 44^{-}, \mathrm{CD}^{2} 33^{-} /$ $\mathrm{CD}_{4} 4^{+}$and $\mathrm{CD} 133 \% \mathrm{CD} 44$ cells were evaluated using Transwell migration and Matrigel-coated Transwell invasion assays, respectively. (A) Representative images of the results obtained from the migration and Matrigel invasion assays. The cells were stained using the Diff-Quick ${ }^{\mathrm{TM}}$ Three-Step Stain kit and scanned using a slide scanner (panoramic MIDI). Scale bar, $200 \mu \mathrm{m}$. (B) The number of migratory and invasive cells in 4 randomly selected fields was determined using a slide scanner (panoramic MIDI). The results are expressed as the means \pm SD of three independent experiments; ${ }^{* *} \mathrm{p}<0.01, \mathrm{CD} 133^{+} / \mathrm{CD} 44^{+}$ vs. CD133 $/ \mathrm{CD} 44^{-}$cells; ${ }^{*}$ p $<0.05 \mathrm{CD} 133^{+} / \mathrm{CD}_{4} 4^{+}$vs. CD133/CD44 cells and $\mathrm{CD} 133^{+} / \mathrm{CD} 44^{+}$vs. $\mathrm{CD} 133^{-} / \mathrm{CD} 44^{+}$cells.
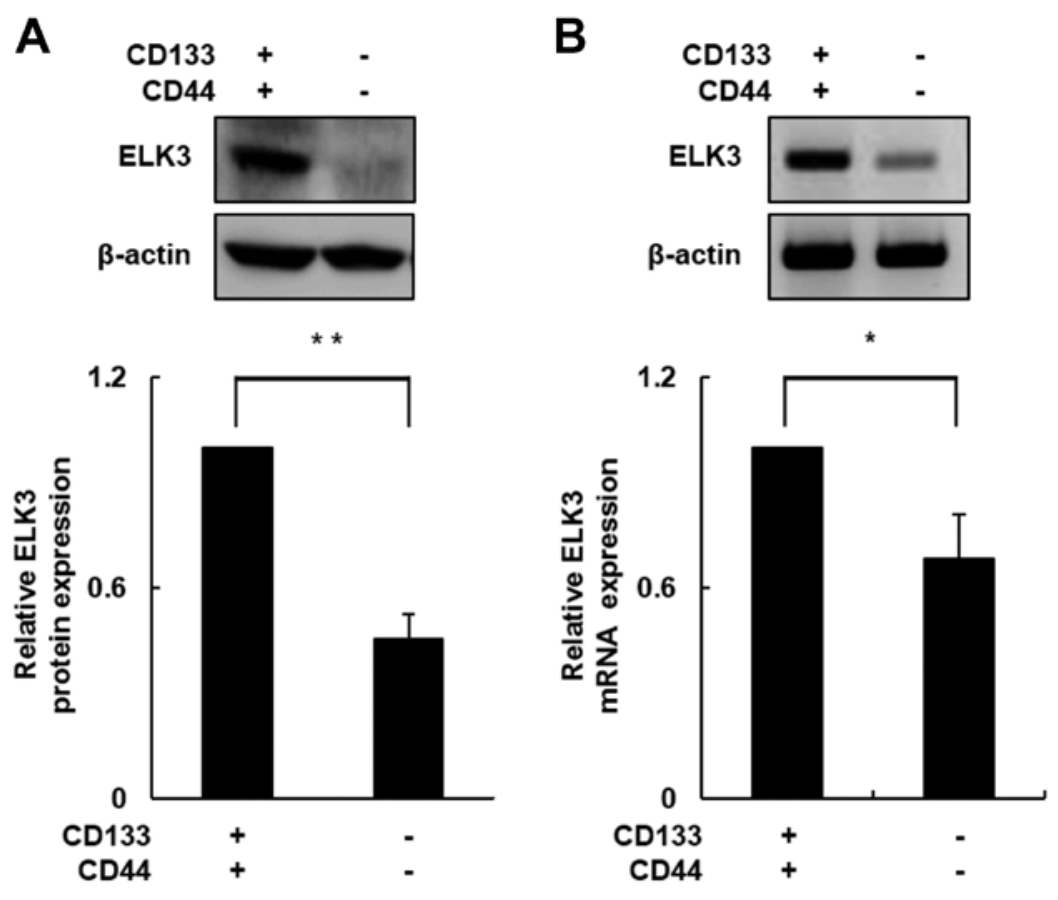

Figure 3. ELK3 is upregulated in CD133+/CD44 ${ }^{+}$LCSCs compared with CD133/CD44 cells. (A) ELK3 expression was measured using western blot analysis with an antibody against ELK3. The band densities were quantified using Multi Gauge imaging software and normalized to $\beta$-actin. The results are expressed as the means $\pm \mathrm{SD}$ of three independent experiments; ${ }^{* *} \mathrm{p}<0.01, \mathrm{CD} 33^{+} / \mathrm{CD} 44^{+}$vs. CD133/CD44 cells. (B) ELK3 mRNA expression levels were measured using RT-PCR with an ELK3-specific primer. The band densities were quantified using Multi Gauge imaging software and normalized to $\beta$-actin. The results are expressed as the means \pm SD of three independent experiments; ${ }^{*} \mathrm{p}<0.05, \mathrm{CD} 133^{+} / \mathrm{CD}_{4} 4^{+}$vs. CD133/CD44 cells. LCSCs, liver cancer stem cells. 
A

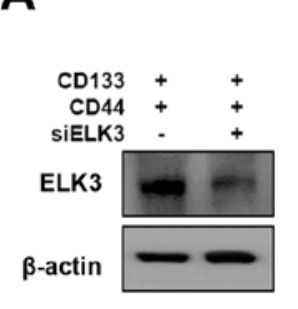

B

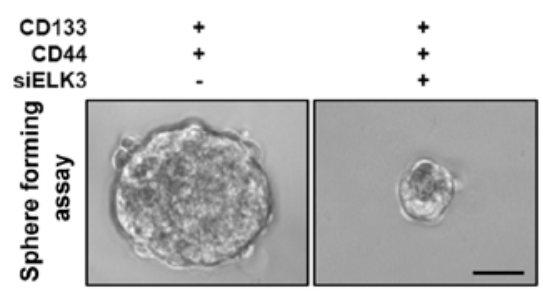

D

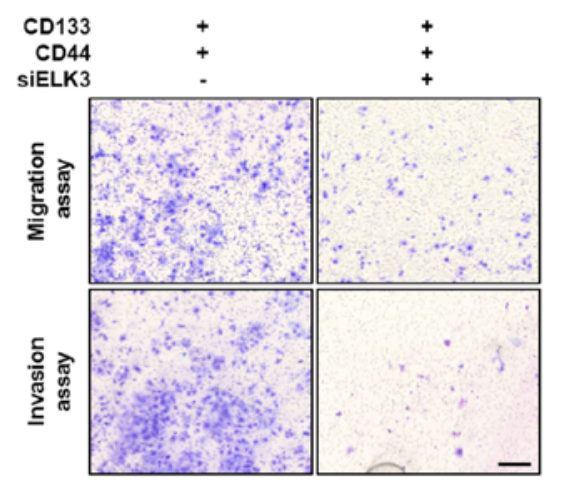

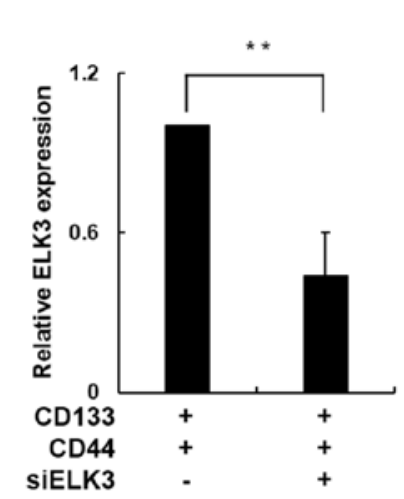

C

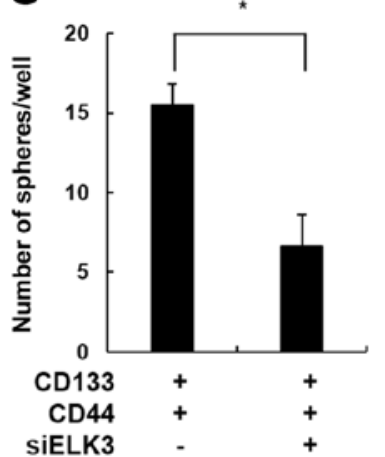

$\mathbf{E}$

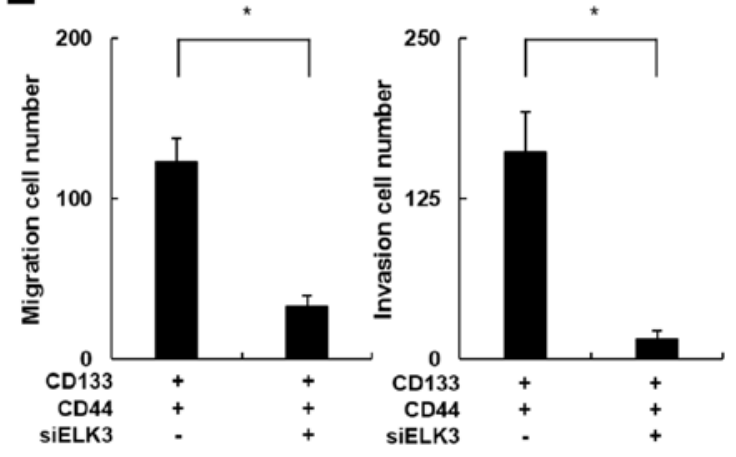

Figure 4. Silencing of ELK3 expression attenuates the metastatic potential of CD133 $/ \mathrm{CD} 44^{+}$LCSCs. Migration and invasion activities in the ELK3-knockdown $\mathrm{CD} 133^{+} / \mathrm{CD} 44^{+}$cells were assessed using a Transwell migration and a Matrigel-coated Transwell invasion assays, respectively. (A) The silencing efficiency was measured using western blot analysis (upper western blot). The density of the band was measured using Multi Gauge imaging software and normalized to $\beta$-actin (lower graph). The results are expressed as the means $\pm \mathrm{SD}$ of three independent experiments; ${ }^{* *}$ p $<0.01, \mathrm{ELK} 3 \mathrm{knockdown} \mathrm{CD} 133^{+} / \mathrm{CD} 44^{+}$cells vs. negative control cells. (B) Clonogenic potential was determined using sphere formation assays. Representative images of spheres were obtained using an inverted microscope (Olympus). Scale bar, $50 \mu \mathrm{m}$. (C) Sphere formation efficiency was quantitatively analyzed. The number of spheres (diameter $>50 \mu \mathrm{m})$ per well $\left(2 \times 10^{2}\right.$ cells/well) was determined using an inverted microscope (Olympus). The results are expressed as the mean \pm SD of three independent experiments; ${ }^{*} \mathrm{p}<0.05$, ELK3-knockdown CD133 ${ }^{+} \mathrm{CD} 44^{+}$group vs. negative control group. (D) Representative image of the Transwell migration and Matrigel invasion assays. The cells were stained using the Diff-Quick ${ }^{\mathrm{TM}}$ Three-Step Stain kit and scanned using a slide scanner (panoramic MIDI). Scale bar, $200 \mu \mathrm{m}$. (E) The migratory and invasive cells in 4 randomly selected fields were counted using a slide scanner (panoramic MIDI). The results are expressed as the means \pm SD of three independent experiments; ${ }^{*} \mathrm{p}<0.05$, ELK3-knockdown CD133 $/ \mathrm{CD} 44^{+}$group vs. negative control group.

fibrogenesis (26). Acquiring cell motility is necessary for the transition from an epithelial to a mesenchymal phenotype $(27,28)$. We used western blot assays to determine whether ELK3 protein levels differ between $\mathrm{CD} 133^{+} / \mathrm{CD} 44^{+}$and CD133\%CD44- cells. As shown in Fig. 3A, the ELK3 protein level was increased $\sim 2.5$-fold in the $\mathrm{CD} 133^{+} / \mathrm{CD} 44^{+}$cells compared with the level in the CD133\%/CD44- cells $(\mathrm{p}<0.01)$. Next, we conducted RT-PCR to measure mRNA expression levels of ELK3 in both subpopulations of cells. Similar to the ELK3 protein level, the ELK3 mRNA expression level was increased nearly 1.5 -fold in the $\mathrm{CD} 133^{+} / \mathrm{CD} 44^{+}$cells compared with the level in the CD133-/CD44- cells (Fig. 3B; p<0.05). These results indicated that ELK3 expression was upregulated in the $\mathrm{CD} 133^{+} / \mathrm{CD} 44^{+}$cells and that the upregulation of ELK3 enhanced HCC cell migration and invasion.

ELK3 knockdown attenuates the metastatic potential of

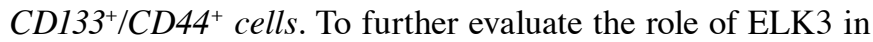
$\mathrm{CD} 133^{+} / \mathrm{CD}_{4} 4^{+}$cell migration and invasion, we transfected $\mathrm{CD} 133^{+} / \mathrm{CD}_{4} 4^{+}$cells with an siRNA targeting ELK3. Western blot analysis of the siRNA silencing efficiency demonstrated that ELK 3 expression decreased by $\sim 60 \%$ in the siELK3-transfected cells when compared with the negative control cells (Fig. 4A; $\mathrm{p}<0.01)$. The clonogenic potential of ELK3-knockdown $\mathrm{CD} 133^{+} / \mathrm{CD} 44^{+}$cells was measured using a sphere formation assay. As shown in Fig. 4B, the size of the spheres formed by the ELK3-knockdown CD133 ${ }^{+} / \mathrm{CD}_{4} 4^{+}$cells was significantly decreased compared with the size of the spheres formed by the negative control cells. The control $\mathrm{CD} 133^{+} / \mathrm{CD} 44^{+}$ cells formed an average of 15 spheres, whereas the ELK3-

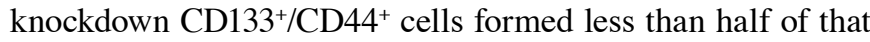
number (Fig. 4C; p<0.05). Next, we conducted a Transwell cell migration assay in the ELK3-knockdown $\mathrm{CD} 133^{+} / \mathrm{CD} 44^{+}$ cells (Fig. 4D, upper panel). Notably, the number of migratory cells was decreased by $70 \%$ in the ELK3-knockdown $\mathrm{CD}_{133}{ }^{+}$ $\mathrm{CD} 44^{+}$cells compared with this number noted in the negative control cells (Fig. 4E; p<0.05). In addition, similar results were obtained using the Matrigel-coated Transwell invasion assay (Fig. 4D, lower panel). The number of cells that invaded the Matrigel was decreased by $\sim 90 \%$ in the ELK3-knockdown $\mathrm{CD} 133^{+} / \mathrm{CD}_{4} 4^{+}$cells compared with this number in the negative control group (Fig. 4E; p<0.05). Collectively, these results indicate that ELK3 expression is associated with the migration and invasion of $\mathrm{CD}_{133}{ }^{+} / \mathrm{CD} 44^{+}$cells. 
A

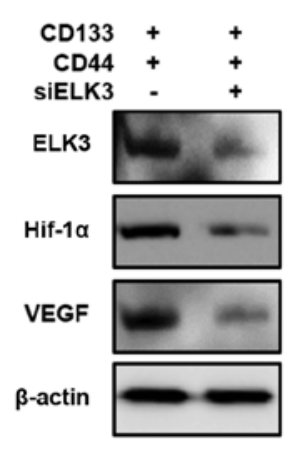

B
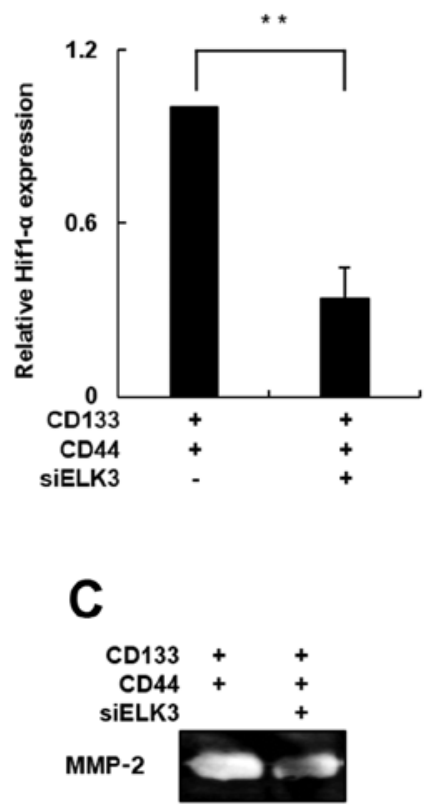
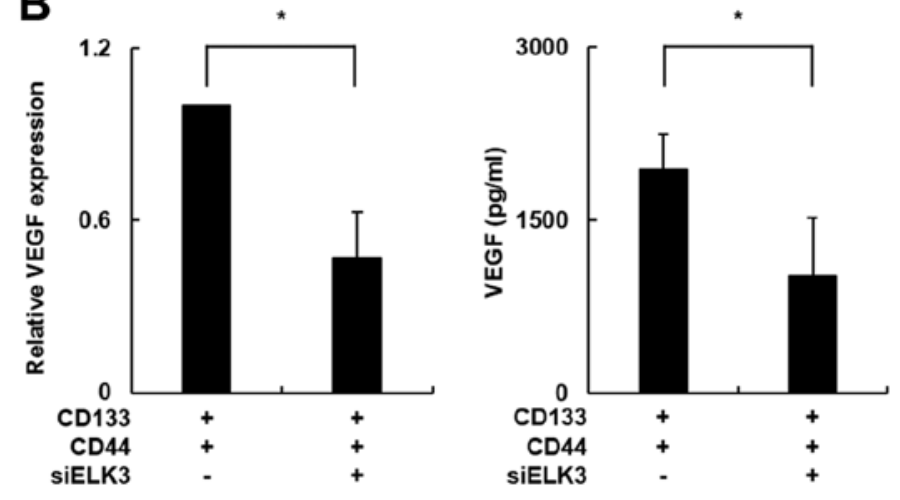

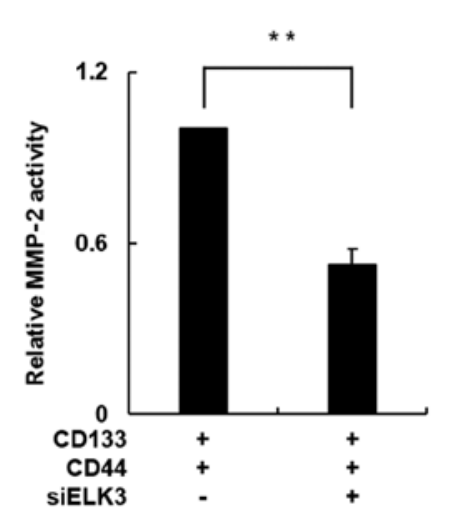

Figure 5. ELK3 silencing inhibits metastasis-associated signaling pathways. (A) Protein expression levels in siELK3-transfected CD133 $/$ CD44 ${ }^{+}$and negative control cells were evaluated using western blot analysis. The band density was measured using Multi Gauge imaging software and normalized to $\beta$-actin. The results are expressed as the means \pm SD of three independent experiments; ${ }^{* *}$ p $<0.01$, ELK 3 knockdown CD $133^{+} / C D 44^{+}$group vs. the negative control group. (B) Secreted VEGF levels in cell supernatants were measured using VEGF-specific ELISA. The results are expressed as the means \pm SD of three independent experiments; "p $<0.05$, ELK3 knockdown CD133 ${ }^{+} / \mathrm{CD} 44^{+}$group vs. negative control group. (C) The enzymatic activity of MMP-2 in ELK3 knockdown cells was measured using gelatin zymography. Relative enzymatic activity was determined by measuring the optical density of the MMP-2 band. The results are expressed as the means \pm SD of three independent experiments; ${ }^{* *} \mathrm{p}<0.01$, ELK3 knockdown CD133 ${ }^{+} / \mathrm{CD} 44^{+}$group vs. the negative control group.

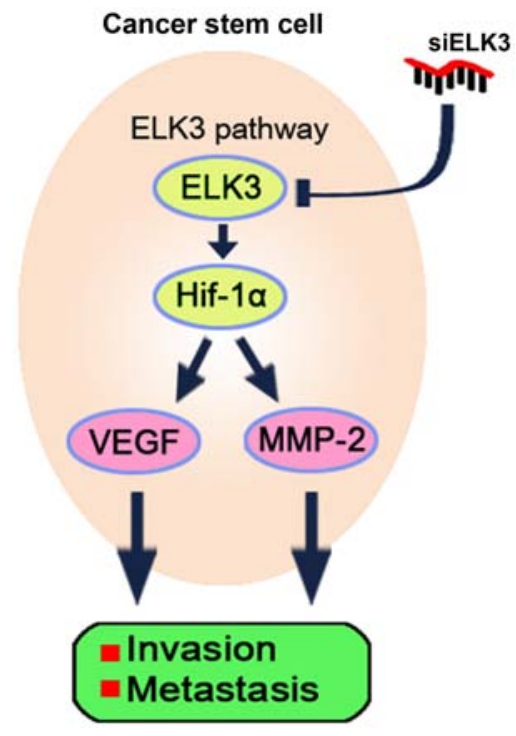

Figure 6. Schematic representation of HIF-1 $\alpha$ regulation by ELK3 in LCSCs during cancer metastasis and invasion. Huh7 $\mathrm{CD} 133^{+} / \mathrm{CD} 44^{+} \mathrm{LCSCs}$ have high metastatic and invasive potential due to the overexpression of ELK3. ELK3 participates in the process of cancer metastasis and invasion via regulation of the HIF-1 $\alpha$ signaling pathway. Silencing of ELK3 expression in $\mathrm{CD} 133^{+} / \mathrm{CD} 44^{+} \mathrm{LCSC}$ attenuated the metastatic and invasive potential via modulation of the HIF-1 $\alpha$ signaling pathway. LCSCs, liver cancer stem cells.

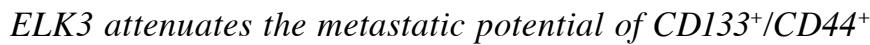
cells by regulating the HIF-1 $\alpha$ signaling pathway. To investigate the molecular mechanism underlying the ELK3-mediated properties of $\mathrm{CD} 133^{+} / \mathrm{CD} 44^{+}$cells, we focused on the relationship between ELK3 and expression of its target gene HIF-1 $\alpha$. Previous studies revealed that several genes including Egr-1, PAI-1 and HIF-1 $\alpha$ are ELK3 target genes by forming ternary complexes. Among these target genes, HIF-1 $\alpha$ is known to stimulate angiogenic and metastatic responses by activating transcription of the genes encoding several growth factors, including VEGF and MMP-2 (19-23,35,36).

To this end, we evaluated the expression of HIF-1 $\alpha$ in the ELK3-knockdown $\mathrm{CD} 133^{+} / \mathrm{CD} 44^{+}$cells. The HIF-1 $\alpha$ protein level was decreased by $\sim 70 \%$ in the ELK3-knockdown CD133 ${ }^{+} /$ $\mathrm{CD} 44^{+}$cells compared with this level noted in the negative control cells (Fig. 5A; $p<0.01$ ). The VEGF protein level was significantly decreased by $\sim 60 \%$ in the ELK3-knockdown $\mathrm{CD} 33^{+} / \mathrm{CD} 44^{+}$cells compared with this level in the negative control cells (Fig. 5A; p <0.05), and a VEGF-specific ELISA demonstrated that VEGF secretion was decreased by $\sim 50 \%$ in the ELK3-knockdown $\mathrm{CD} 133^{+} / \mathrm{CD} 44^{+}$cells compared with the secretion observed in the negative control group (Fig. 5B; $\mathrm{p}<0.05)$. These result suggested that ELK3 knockdown has an inhibitory effect on VEGF-induced angiogenesis. 
Therefore, we performed a gelatin zymography assay to determine the enzymatic activity of MMP-2 in the ELK3-knockdown CD133 $/$ CD $44^{+}$cells since recent studies have demonstrated that MMP-2 participates in the cancer metastasis process and is also known to correlate with HIF-1 $\alpha$ expression $(36,38)$. As shown in Fig. 5C, the enzymatic activity of MMP-2 was decreased by $~ 50 \%$ in the ELK3-knockdown $\mathrm{CD} 133^{+} / \mathrm{CD} 44^{+}$cells compared with that in the negative control group $(\mathrm{p}<0.05)$. Together, these results indicate that silencing of ELK 3 expression in the $\mathrm{CD} 133^{+} / \mathrm{CD} 44^{+}$cells can decrease the activity of metastasis-associated molecules by inhibiting HIF-1 $\alpha$ expression.

Collectively, these data demonstrated that ELK3 overexpression promotes metastasis in $\mathrm{CD} 133^{+} / \mathrm{CD} 44^{+}$cells and that inhibiting ELK3 expression attenuates the metastatic potential

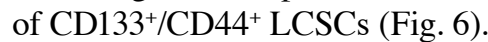

\section{Discussion}

HCC metastasis occurs through a series of several complex steps. Briefly, metastatic cancer cells escape from the primary cancer, enter the blood circulation and ultimately colonize a new organ and form metastasis (40). As multiple complex steps are required for this process, the majority of cancer cells rarely metastasize to other organs. Recent studies have shown that CSCs comprise an extremely small subpopulation of cancer cells and have high metastatic potential (5-7). Therefore, several cancers including HCC, are very difficult to cure using standard cancer chemotherapy treatments due to the persistence of CSCs (41). Cancer cells that survive anticancer therapy can initiate metastasis, thereby contributing to a poor prognosis. Therefore, identifying and specifically targeting CSCs may represent a promising therapeutic strategy for treating cancer. Consistent with this hypothesis, numerous studies have investigated methods for identifying and targeting CSCs among the general population of cancer cells.

Many specific cell surface markers have been identified and characterized at the biological and clinical level (8). Among these markers, CD133 and CD44 play a well-established role in the metastatic potential of LCSCs $(8,10,14,42)$. Notably, several recent studies reported that the expression of CD133 or CD44 alone is not sufficient to account for all of the biological properties of CSCs $(43,44)$. Therefore, several studies have investigated whether CSCs that co-express CD133 and CD44 represent a more potent CSC subpopulation $(45,46)$. These studies revealed that the co-expression of CD133 and CD44 is a more specific LSCS biomarker and a more valuable prognostic indicator in HCC (44-46). In the present study, we demonstrated that $\mathrm{CD} 133^{+} / \mathrm{CD} 44^{+}$cells have increased metastatic potential compared with non-CD133 ${ }^{+} / \mathrm{CD} 44^{+}$cells using cell migration and invasion assays.

After evaluating the metastatic potential of CD $133^{+} / \mathrm{CD} 44^{+}$ LCSCs, we investigated the molecular mechanisms underlying these properties. In a previous study, we revealed that $\mathrm{CD}_{133^{+}}$LCSCs mediate radiation resistance in human HCC by regulating MAPK signaling pathways (47). In addition, a recent study revealed that CD133 expression was modulated by the ERK1/2 and Src signaling pathways in pancreatic cancer and that CD133 promoted cancer invasion and metastasis by activating an EMT regulatory feedback loop (48).
CD44 maintains the high basal level of motility in breast cancer cells by forming a complex with ERK1 and 2, and CD168 (15). Both of these studies concluded that CD133 and CD44 are associated with the MAPK signaling pathways such as the ERK pathway. Furthermore, the results of our previous study revealed that ELK3 contributes to the process of EMT via MAPK/ELK3/egr-1 signaling (26). Moreover, as previous studies have demonstrated that EMT promotes a mesenchymal phenotype and consequently enhances cell motility, EMT is regarded as a contributing factor to metastasis and invasion in various types of cancer. As ELK3 expression is associated with cell migration, vasculogenesis and wound healing $(24,25)$, we examined the potential role of ELK3 in the mechanisms underlying metastasis and invasion in LCSCs.

In the present study, ELK3 expression levels in $\mathrm{CD}_{133^{+}} /$ $\mathrm{CD} 44^{+}$cells were significantly elevated compared with CD133-/CD44- cells. These results suggest that ELK3 plays a specific role in cancer metastasis and invasion in LCSCs. Furthermore, we investigated the molecular mechanisms underlying the function of ELK3 in $\mathrm{CD} 133^{+} / \mathrm{CD} 44^{+} \mathrm{LCSC}$ metastasis by transfecting CD $133^{+} / \mathrm{CD} 44^{+} \mathrm{LCSC}$ with ELK3-specific siRNA. Notably, we found that silencing ELK3 expression inhibited LCSC metastasis and invasion. Previous studies demonstrated that ELK3 participates in the regulation of various genes, including c-fos, egr-1, and PAI-1. In addition, ELK3 is known as a regulator of HIF-1 $\alpha$ expression by modulating HIF- $1 \alpha$ stability $(21-23,30,31)$. HIF- $1 \alpha$ plays a key role in the induction of cancer invasion, metastasis and angiogenesis, as well as in cancer growth, glucose metabolism, and other metastasis-associated signaling pathways (32-36). Notably, HIF-1 $\alpha$ is a key regulator of cancer metastasis and invasion in $\mathrm{HCC}(35,36)$. In the present study, the HIF-1 $\alpha$ protein level was decreased by $\sim 60 \%$ in the ELK3-knockdown $\mathrm{CD} 133^{+} / \mathrm{CD} 44^{+}$cells. Consistent with this observation, the activity of VEGF and MMP-2 was significantly decreased in the ELK3-knockdown CD133 ${ }^{+} / \mathrm{CD}_{4} 4^{+}$ LCSCs. These results indicate that ELK3 expression, and the activity of VEGF and MMP-2 are directly associated with the co-expression of the cell surface markers CD133 and CD44 and that the co-expression of these markers is a more specific and reliable marker of HCC compared to the expression of either CD133 or CD44 alone.

According to these results, we conclude that Huh7 CD $133^{+} / \mathrm{CD}_{4} 4^{+}$LCSCs have high metastatic and invasive potential due to the overexpression of ELK3. Moreover, we found that silencing of ELK3 expression in the CD133 $/ \mathrm{CD} 44^{+}$ LCSCs attenuated the metastatic and invasive potential via modulation of the HIF-1 $\alpha$ signaling pathway (Fig. 6).

A better understanding of the cellular and molecular mechanisms underlying LCSC metastasis and invasion is essential to improving the efficacy of therapies designed to suppress HCC metastasis in the clinical setting. In this regard, the novel findings reported in the present study indicate that ELK3 expression contributes to the metastatic potential of LCSCs and that silencing of ELK3 expression can reduce the metastatic and invasive potential of LCSCs by regulating HIF-1 $\alpha$. In conclusion, modulation of ELK3 expression may represent a novel therapeutic approach for preventing the process of cancer metastasis and invasion in HCC. 


\section{Acknowledgements}

The present study was supported by grants from the National Research Foundation of Korea funded by the Korea government (NRF-2015R1A2A1A15052783) and of the Ministry of Science, ICT and Future Planning through the National Research Foundation.

\section{References}

1. Torre LA, Bray F, Siegel RL, Ferlay J, Lortet-Tieulent J and Jemal A: Global cancer statistics, 2012. CA Cancer J Clin 65 87-108, 2015

2. Guo Z, Zhong JH, Jiang JH, Zhang J, Xiang BD and Li LQ: Comparison of survival of patients with BCLC stage A hepatocellular carcinoma after hepatic resection or transarterial chemoembolization: A propensity score-based analysis. Ann Surg Oncol 21: 3069-3076, 2014

3. Ueno M, Uchiyama K, Ozawa S, Hayami S, Shigekawa Y, Tani M and Yamaue H: Adjuvant chemolipiodolization reduces early recurrence derived from intrahepatic metastasis of hepatocellular carcinoma after hepatectomy. Ann Surg Oncol 18: 3624-3631, 2011.

4. El-Serag HB, Marrero JA, Rudolph L and Reddy KR: Diagnosis and treatment of hepatocellular carcinoma. Gastroenterology 134 1752-1763, 2008

5. Clarke MF, Dick JE, Dirks PB, Eaves CJ, Jamieson CH, Jones DL, Visvader J, Weissman IL and Wahl GM: Cancer stem cells - perspectives on current status and future directions: AACR Workshop on Cancer Stem Cells. Cancer Res 66: 9339-9344, 2006.

6. Visvader JE and Lindeman GJ: Cancer stem cells in solid tumours: Accumulating evidence and unresolved questions. Nat Rev Cancer 8: 755-768, 2008.

7. Yamashita T and Wang XW: Cancer stem cells in the development of liver cancer. J Clin Invest 123: 1911-1918, 2013.

8. Lee TK, Cheung VC and Ng IO: Liver tumor-initiating cells as a therapeutic target for hepatocellular carcinoma. Cancer Lett 338: $101-109,2013$

9. Grosse-Gehling P, Fargeas CA, Dittfeld C, Garbe Y, Alison MR, Corbeil D and Kunz-Schughart LA: CD133 as a biomarker for putative cancer stem cells in solid tumours: Limitations, problems and challenges. J Pathol 229: 355-378, 2013.

10. Kohga K, Tatsumi T, Takehara T, Tsunematsu H, Shimizu S, Yamamoto M, Sasakawa A, Miyagi T and Hayashi N: Expression of CD133 confers malignant potential by regulating metalloproteinases in human hepatocellular carcinoma. J Hepatol 52: 872-879, 2010.

11. Ma S, Chan KW, Hu L, Lee TK, Wo JY, Ng IO, Zheng BJ and Guan XY: Identification and characterization of tumorigenic liver cancer stem/progenitor cells. Gastroenterology 132: 2542-2556, 2007.

12. Yan M, Li H, Zhu M, Zhao F, Zhang L, Chen T, Jiang G, Xie H, Cui Y, Yao M, et al: G protein-coupled receptor 87 (GPR87) promotes the growth and metastasis of $\mathrm{CD}_{133^{+}}$cancer stem-like cells in hepatocellular carcinoma. PLoS One 8: e61056, 2013.

13. Hong SW, Hur W, Choi JE, Kim JH, Hwang D and Yoon SK: Role of ADAM17 in invasion and migration of CD133-expressing liver cancer stem cells after irradiation. Oncotarget 7: 23482-23497, 2016.

14. Xie Z, Choong PF, Poon LF, Zhou J, Khng J, Jasinghe VJ, Palaniyandi S and Chen CS: Inhibition of CD44 expression in hepatocellular carcinoma cells enhances apoptosis, chemosensitivity, and reduces tumorigenesis and invasion. Cancer Chemother Pharmacol 62: 949-957, 2008.

15. Hamilton SR, Fard SF, Paiwand FF, Tolg C, Veiseh M, Wang C, McCarthy JB, Bissell MJ, Koropatnick J and Turley EA: The hyaluronan receptors CD44 and Rhamm (CD168) form complexes with ERK1,2 that sustain high basal motility in breast cancer cells. J Biol Chem 282: 16667-16680, 2007.

16. Fillmore $C$ and Kuperwasser C: Human breast cancer stem cell markers CD44 and CD24: Enriching for cells with functional properties in mice or in man? Breast Cancer Res 9: 303, 2007.

17. Du L, Wang H, He L, Zhang J, Ni B, Wang X, Jin H, Cahuzac N, Mehrpour M, Lu Y, et al: CD44 is of functional importance for colorectal cancer stem cells. Clin Cancer Res 14: 6751-6760, 2008
18. Buchwalter G, Gross C and Wasylyk B: Ets ternary complex transcription factors. Gene 324: 1-14, 2004.

19. Ducret C, Maira SM, Lutz Y and Wasylyk B: The ternary complex factor Net contains two distinct elements that mediate different responses to MAP kinase signalling cascades. Oncogene 19: 5063-5072, 2000.

20. Giovane A, Pintzas A, Maira SM, Sobieszczuk P and Wasylyk B: Net, a new ets transcription factor that is activated by Ras. Genes Dev 8: 1502-1513, 1994

21. Buchwalter G, Gross C and Wasylyk B: The ternary complex factor Net regulates cell migration through inhibition of PAI-1 expression. Mol Cell Biol 25: 10853-10862, 2005.

22. Ayadi A, Zheng H, Sobieszczuk P, Buchwalter G, Moerman P, Alitalo K and Wasylyk B: Net-targeted mutant mice develop a vascular phenotype and up-regulate egr-1. EMBO J 20: 5139-5152, 2001.

23. Wasylyk C, Zheng H, Castell C, Debussche L, Multon MC and Wasylyk B: Inhibition of the Ras-Net (Elk-3) pathway by a novel pyrazole that affects microtubules. Cancer Res 68: 1275-1283, 2008.

24. Zheng H, Wasylyk C, Ayadi A, Abecassis J, Schalken JA, Rogatsch H, Wernert N, Maira SM, Multon MC and Wasylyk B: The transcription factor Net regulates the angiogenic switch. Genes Dev 17: 2283-2297, 2003.

25. Ayadi A, Suelves M, Dollé P and Wasylyk B: Net, an Ets ternary complex transcription factor, is expressed in sites of vasculogenesis, angiogenesis, and chondrogenesis during mouse development. Mech Dev 102: 205-208, 2001.

26. Li TZ, Kim SM, Hur W, Choi JE, Kim JH, Hong SW, Lee EB, Lee JH and Yoon SK: Elk-3 contributes to the progression of liver fibrosis by regulating the epithelial-mesenchymal transition. Gut Liver: Aug 19, 2016 (Epub ahead of print). doi: $10.5009 / \mathrm{gn} 115566$.

27. Thiery JP: Epithelial-mesenchymal transitions in tumour progression. Nat Rev Cancer 2: 442-454, 2002.

28. Thiery JP, Acloque H, Huang RY and Nieto MA: Epithelialmesenchymal transitions in development and disease. Cell 139: 871-890, 2009.

29. Książkiewicz M, Markiewicz A and Zaczek AJ: Epithelialmesenchymal transition: A hallmark in metastasis formation linking circulating tumor cells and cancer stem cells. Pathobiology 79: 195-208, 2012.

30. Gross C, Dubois-Pot H and Wasylyk B: The ternary complex factor Net/Elk-3 participates in the transcriptional response to hypoxia and regulates HIF-1 alpha. Oncogene 27: 1333-1341, 2008.

31. Gross C, Buchwalter G, Dubois-Pot H, Cler E, Zheng H and Wasylyk B: The ternary complex factor net is downregulated by hypoxia and regulates hypoxia-responsive genes. Mol Cell Biol 27: 4133-4141, 2007.

32. Xia L, Mo P, Huang W, Zhang L, Wang Y, Zhu H, Tian D, Liu J, Chen Z, Zhang Y, et al: The TNF- $\alpha /$ ROS/HIF-1-induced upregulation of FoxMI expression promotes HCC proliferation and resistance to apoptosis. Carcinogenesis 33: 2250-2259, 2012.

33. Xu Z, Liu E, Peng C, Li Y, He Z, Zhao C and Niu J: Role of hypoxia-inducible-1 $\alpha$ in hepatocellular carcinoma cells using a Tet-on inducible system to regulate its expression in vitro. Oncol Rep 27: 573-578, 2012.

34. Denko NC: Hypoxia, HIF1 and glucose metabolism in the solid tumour. Nat Rev Cancer 8: 705-713, 2008.

35. Luo D, Wang Z, Wu J, Jiang C and Wu J: The role of hypoxia inducible factor-1 in hepatocellular carcinoma. Biomed Res Int 2014: 409272, 2014.

36. Xiang ZL, Zeng ZC, Fan J, Tang ZY, Zeng HY and Gao DM: Gene expression profiling of fixed tissues identified hypoxia-inducible factor-1 $\alpha$, VEGF, and matrix metalloproteinase-2 as biomarkers of lymph node metastasis in hepatocellular carcinoma. Clin Cancer Res 17: 5463-5472, 2011.

37. Lin D and Wu J: Hypoxia inducible factor in hepatocellular carcinoma: A therapeutic target. World J Gastroenterol 21: 12171-12178, 2015.

38. Choi SH, Shin HW, Park JY, Yoo JY, Kim DY, Ro WS, Yun CO and Han KH: Effects of the knockdown of hypoxia inducible factor-1 $\alpha$ expression by adenovirus-mediated shRNA on angiogenesis and tumor growth in hepatocellular carcinoma cell lines. Korean J Hepatol 16: 280-287, 2010.

39. Zhu Z, Hao X, Yan M, Yao M, Ge C, Gu J and Li J: Cancer stem/progenitor cells are highly enriched in $\mathrm{CD} 133^{+} \mathrm{CD} 44^{+}$population in hepatocellular carcinoma. Int J Cancer 126: 2067-2078, 2010 . 
40. Chambers AF, Groom AC and MacDonald IC: Dissemination and growth of cancer cells in metastatic sites. Nat Rev Cancer 2: 563-572, 2002

41. Pardal R, Clarke MF and Morrison SJ: Applying the principles of stem-cell biology to cancer. Nat Rev Cancer 3: 895-902, 2003.

42. Yang ZF, Ho DW, Ng MN, Lau CK, Yu WC, Ngai P, Chu PW, Lam CT, Poon RT and Fan ST: Significance of CD90 ${ }^{+}$cancer stem cells in human liver cancer. Cancer Cell 13: 153-166, 2008.

43. Salnikov AV, Kusumawidjaja G, Rausch V, Bruns H, Gross W, Khamidjanov A, Ryschich E, Gebhard MM, Moldenhauer G, Büchler MW, et al: Cancer stem cell marker expression in hepatocellular carcinoma and liver metastases is not sufficient as single prognostic parameter. Cancer Lett 275: 185-193, 2009.

44. Liu LL, Fu D, Ma Y and Shen XZ: The power and the promise of liver cancer stem cell markers. Stem Cells Dev 20: 2023-2030, 2011.
45. Hou Y, Zou Q, Ge R, Shen F and Wang Y: The critical role of $\mathrm{CD} 133^{+} \mathrm{CD} 44^{\text {+high }}$ tumor cells in hematogenous metastasis of liver cancers. Cell Res 22: 259-272, 2012.

46. Chen KL, Pan F, Jiang H, Chen JF, Pei L, Xie FW and Liang HJ: Highly enriched CD $133^{+} \mathrm{CD} 44^{+}$stem-like cells with $\mathrm{CD} 133^{+} \mathrm{CD} 44^{\text {high }}$ metastatic subset in HCT116 colon cancer cells . Clin Exp Metastasis 28: 751-763, 2011.

47. Piao LS, Hur W, Kim TK, Hong SW, Kim SW, Choi JE, Sung PS, Song MJ, Lee BC, Hwang D, et al: CD133+ liver cancer stem cells modulate radioresistance in human hepatocellular carcinoma. Cancer Lett 315: 129-137, 2012

48. Ding Q, Miyazaki Y, Tsukasa K, Matsubara S, Yoshimitsu M and Takao S: CD133 facilitates epithelial-mesenchymal transition through interaction with the ERK pathway in pancreatic cancer metastasis. Mol Cancer 13: 15, 2014 